Article

\title{
The Influence of International Education Experience on Host Country-Related Outcomes: An Analysis of Chinese Students' Relationships with South Korean Universities
}

\author{
Hyehyun Hong ${ }^{1, * \mathbb{D}}$, Suman Lee ${ }^{2}$ and Qianqian Tian ${ }^{1}$ \\ 1 Department of Advertising and Public Relations, Chung-Ang University, Seoul 06974, Korea; \\ qianqiantian000@gmail.com \\ 2 Hussman School of Journalism and Media, University of North Carolina at Chapel Hill, Chapel Hill, \\ NC 27599, USA; suman@unc.edu \\ * Correspondence: hhong@cau.ac.kr
}

Received: 19 October 2020; Accepted: 18 November 2020; Published: 20 November 2020

\begin{abstract}
Recognizing the globalization of higher education institutions, this study examined the influence of university-student relationships on host country-related outcomes, including student attitudes, purchase intentions, and policy support. A survey was conducted with Chinese students who had studied or who were currently studying at South Korean universities. Its results showed a significant positive association between Chinese student perceptions of their relationships with host universities and their attitudes toward South Korea. In addition, their positive attitudes led to (i) intentions to purchase Korean products and (ii) policy support for the Korean government. The theoretical and practical implications of study findings are discussed from the perspectives of public diplomacy and the university's role in a highly globalized education system.
\end{abstract}

Keywords: international education experience; higher education institutions; university-student relationship; attitude toward the country; policy support

\section{Introduction}

In the age of globalization, the flow of international students has increased across the world from 2 million in 2000 to 5 million in 2017 [1]. According to UNESCO [1], international students are defined as "students who have crossed a national or territorial border for the purpose of education", typically with student visas. Although the U.S. and the U.K. have had the largest population of international students traditionally, destination countries have become more diverse and South Korea has been one of the emerging countries in this regard. According to national statistics [2], the number of international students in higher education in South Korea increased from 63,952 in 2008 to 89,537 in 2011, and reached 104,262 in 2016. While about 95\% of them come from Asian countries, such as China, Mongolia, Vietnam, and Japan, the proportion of Chinese students is overwhelming; as of 2016, about $73 \%$ of international students came from China alone.

Previous studies (e.g., [3,4]) showed that personal experiences, such as the consumption of foreign products, international business, tours, and study abroad programs, have exerted increasingly substantial impacts on individuals' perceptions of foreign countries. Among diverse personal experiences, international education programs require long-term stays, and thus, provide college students with in-depth experiences of foreign cultures and direct contact with local people. Previous studies have identified outcomes and impacts of international education in many dimensions, including learning outcomes or academic achievement [5], cultural understanding [6], personal development [6], 
employment and career development [5], and institutional prestige/ranking [7]. Most outcome dimensions of international education have been examined at either an individual student level or an institutional level. Not much research has documented the country-related outcomes of international education, except a few studies only in the U.S. context [8-12].

In recognition of the growing number of Chinese students in South Korea, which is one of the top five destination countries hosting Chinese students, this study centered on Chinese students who studied at South Korean universities. Theoretically, the research aimed to examine the influence of international education on country-related outcomes such as international students' attitudes, purchase intentions, and support for a host country's policy. In particular, the focus on host country policy support as an outcome of international education should be highlighted as a major contribution of this study. Policy support and favorable public opinion are fundamental public diplomacy goals that any government wants to achieve but have been neglected in empirical testing [13]. In addition, this study investigated Chinese students' experiences with their host universities by focusing on the organization-public relationship (OPR, hereafter) - a central theoretical framework in public relations. Thus, we proposed and tested a model linking university-student relationships to three specific host-country-related outcomes—students' attitudes, policy support, and purchase intentions. By adopting the OPR, this study provides a comprehensive and useful tool for examining international students' university experiences.

This proposed model also sought to provide a conceptual and evaluative tool to make higher education institutions more sustainable, particularly in the domain of internationalization. In a highly globalized education system, internationalization is a critical aspect of the sustainable development of higher education institutions [14-17]. International students' mobility has been considered a crucial component of internationalization [14,17]. Kioupi and Voulvoulis [18] also highlighted the importance of diversity and inclusion as key sustainability attributes, along with seven others based on the Sustainable Development Goals (SDGs) of higher education programs. The model we proposed and tested in this study will provide further understanding of how to build and maintain mutually beneficial relationships between host universities and international students; these enhanced relationships can influence positive outcomes on the country-level beyond the host universities. This corresponds to what Wilson [19] noted: "internationalization is an increasingly important strategic priority not only for institutions but also for governments, which are increasingly aware of the importance of universities in supporting national and regional competitiveness" (p. 30). The current study will be a valuable addition to the relevant literature, which has been conducted according to a mostly Westernized and English-speaking perspective [17].

\section{Literature Review}

\subsection{Organization-Public Relationship (OPR) as an Indicator of International Students' Experience with Host Universities}

The theoretical framework of OPR has been developed and applied for the past few decades in the field of public relations (PR) [20-24]. From a relational perspective, the fundamental goal and identity of an organization's PR is to build and maintain a favorable relationship with its publics [20-28]. According to Huang [29], OPR is defined as "the degree that the organization and its publics trust one another, agree on one has rightful power to influence, experience satisfaction with each other, and commit oneself to one another" (p. 12). With this definition, Huang [26,29] framed OPR as perceived and subjective rather than objective, identifying four dimensions: trust, control mutuality, satisfaction, and commitment.

According to Hon and Grunig [24], control mutuality refers to the level of agreement regarding power balance or how much rightful power each party has over the other. High control mutuality allows both organizations and publics to exert balanced influence over one another. Next, trust is a more complex concept that refers to "the level of confidence in and willingness to open oneself to the other party" based on three underlying dimensions: integrity (i.e., fairness and justness), dependability 
(i.e., consistency between the saying and doing), and competence (i.e., ability or capability) [24] (p. 3). The third relationship indicator, satisfaction, refers to the level of favorable feeling stemming from how much a given party's expectations are fulfilled by the other party. The last indicator, commitment, refers to the degree to which one party believes that "the relationship is worth spending energy to maintain and promote" [24] (p. 3), and it involves both the party's willingness to continue the relationship (i.e., continuance commitment) and emotional attachment (i.e., affective commitment). Hon and Grunig's [24] conceptualization of OPR and the measurements they developed have served as a cornerstone for OPR research, and have been widely adopted and applied in many subsequent studies $[25,27,28]$.

Previously, many OPR studies have been conducted in university settings, focusing on the university-student relationship $[21,25,27,28,30,31]$. Students are a unique public that performs various roles, namely, (i) major internal constituents, along with faculty and administrative staff, (ii) consumers who receive education services and provide financial resources by paying tuition, and (iii) current and prospective university donors and supporters [31]. It seems natural, however, that if students perceive these relationships as poor, they can also be activists [31]. As such, university-student relationships are based on the interdependence of students and universities, and they produce diverse cognitive, affective, and behavioral consequences [31]. For example, in a university setting, Ki and Hon [28] showed that OPR has a significant influence on attitude toward the university, which predicts supportive behavioral intentions for the university. Sung and Yang [30] also showed that, along with the perceived university reputation, students' perceived relationships with the university appeared to positively impact their supportive behavioral intentions, including future willingness to donate to the university as alumni, to participate in the university's continuing education, and to recommend the university. Bruning [21] found a significant association between students' perceived relationships with the university and their actual retention behavior. In addition, Mohammed [32] concluded that relationship quality is a significant predictor of how students perceive the university's performance in terms of emotional engagement, emotional touch, and academic quality.

Even though many studies have found that OPR positively impacts attitudes, behavioral intentions, and behaviors at an organizational level, examinations of the scope of its influence beyond organizations remain scarce. However, international students play important roles as host university constituents and as advocates for host countries. Their educational experience provides quality opportunities to interact with the host country and its people directly.

It is widely known that over and beyond mass media channels, first-hand experience (e.g., travel, business, and education) has become a major route for people to acquire knowledge and form opinions and attitudes about other countries [3,4,33-35]. Among diverse personal experiences, international education provides young adults such as college students with an opportunity to learn in-depth about foreign countries and form positive attitudes toward them. In this regard, Byrne and Hall [36] noted that "international education is a vehicle that enables and fosters authentic engagement, exchange and collaboration at the individual, institutional, and community levels" (p. 425).

Studies on the decades-long success of the US Fulbright Program have evidenced its impacts on creating positive perceptual, attitudinal, and behavioral changes in US-visiting students and scholars [8,9,11,12]. In a more recent study, Kim [37] found similar outcomes resulting from the Humphrey Fellowship Program; international fellows in the program acquired a better understanding of the U.S. and changed their pre-existing attitudes and perceptions by directly interacting with U.S. citizens at work or home. The information gained from face-to-face interactions was considered highly credible by the fellows. Regarding the program's long-term benefit, fellows saw it as favorable to the U.S. because the program would generate US-friendly global leaders and policy supporters. The impacts of international education are not limited to inbound programs. Analyzing American university branch campuses in Qatar, Eastwood [38] showed how American education institutions have contributed to the development of higher education in the region and turned negative public opinion toward the U.S. into positive. 
Thus, based on the literature mentioned above, we proposed the following hypothesis regarding the influence of the international education experience on the attitude toward the host country. The relationship with the host university represented the international education experience.

Hypothesis 1. The university-student relationship perceived by international students is positively associated with their attitude toward the host country.

\subsection{Public Diplomacy and the Influence of International Education on Host Country-Related Outcomes}

Public diplomacy plays a critical role in communicating with the publics in other countries; it encompasses the purposive and comprehensive activities of state and nonstate actors representing a host country to influence and build relationships with foreign publics in a target country $[9,39]$. Tuch [40] defined it as "communicating with foreign publics in an attempt to bring about understanding for its nation's ideas and ideals, its institutions and culture, as well as its national goals and policies" (p. 3). Sharp [41], meanwhile, described it as "the process by which direct relations are pursued with a country's people to advance the interests and extend the values of those being represented" (p. 106). In sum, scholars share a view of public diplomacy as concerned with building and maintaining relationships with foreign publics to achieve host countries' interests and policy goals.

Without public support and favorable public opinion, no government can achieve its policy goals. Foreign policy targeting other countries is no exception to this reality. Countries, therefore, care a great deal about how publics in other countries think and feel about them. Publics in other countries include consumers who purchase imported goods and services, tourists and students who visit and study overseas, investors who build factories and hold shares in other countries, and voters who influence foreign policy toward other countries. Building and maintaining positive public attitudes and favorable public opinion in other countries is thus a viable national interest for any country.

In order to achieve national interests and policy goals, countries conduct public diplomacy through a wide range of activities. Cull [8] identified and explained the following five categories of purposive and comprehensive public diplomacy activities: (i) listening, (ii) advocacy, (iii) cultural diplomacy, (iv) exchange diplomacy, and (v) international broadcasting (or news). Listening involves gathering information about foreign public opinion before making policy decisions and active listening is critical to two-way communication. Advocacy involves promoting a country's policy positions or interests targeting foreign publics. Cultural diplomacy involves sharing a country's cultural attraction and heritage with foreign publics (e.g., the British Council). Exchange diplomacy involves people to people interaction through short- or long-term study in or visits to foreign countries (e.g., the Fulbright Scholarship). International broadcasting involves engaging with foreign publics using television, radio, and the Internet in the form of news (e.g., BBC World Service).

While traditional public diplomacy highlights the government's role in these activities, recently more attention has been directed toward the role of nonstate actors and the effectiveness of their relationship-building in contemporary or new public diplomacy $[8,11,12]$. Publics in other countries could easily perceive public diplomacy activities explicitly and visibly led by foreign governments as propaganda rather than two-way relationship building. Therefore, many governments play a supportive role in creating environments in which nonstate private sector actors such as corporations, educational institutions, associations, and nongovernmental organizations actively interact with publics and their counterparts in other countries. Fitzpatrick [42] described this trend as privatized public diplomacy or public-private partnership. In this regard, educational institutions are one of the major nonstate actors for promoting favorable image and attitude toward the host country among young adults and college students.

Lima [43] identified the three main functions of educational exchanges: (i) mutual understanding, (ii) positive country image, and (iii) support for host country policies. Kelman [44] pointed out that "the exchange experience is most likely to produce favorable attitudes if it provides new information about the host country in the context of a positive interaction with some of its people" (p. 78). 
Thus, international education and exchange programs have been considered an important form of public diplomacy that builds mutual trust and favorable relationships with foreign publics $[8,9,36]$. For example, studies have shown that the permanent presence of U.S. universities in the region has become an effective U.S. soft power asset, nurturing future Arab leaders who favor American values, such as free speech and democratic systems. Hayden [45] also showed how a Saudi American Exchange program facilitated intercultural communication and mutual understanding through in-person collaboration between Arab and U.S. students. Thus, educational/professional exchange programs are often considered as an important player for building relationships between the U.S. and the rest of the world [46].

Previous studies have shown that positive attitudes toward foreign countries are likely to generate positive behavioral outcomes for said countries. For example, Kotler and Gertner [47] asserted that country image influences people's purchasing, investing, residence, and travel decisions. Lee, Rodriguez, and Sar [48] found a positive relationship between country image and people's willingness to visit. Papadopoulos and Heslop [49] found that country image and nation branding play important roles in foreign investment decision-making. Extensive research regarding country-of-origin (e.g., [50]) and nation branding (e.g., [51]) has shown a robust relationship between country image and behavioral intentions such as purchase intentions and willingness to visit. Following these studies, the next hypothesis predicted the influence of attitude toward the host country on the purchase intention of the host country's products, referring to an individual's willingness to buy them.

Hypothesis 2. Attitude toward the host country is positively associated with the intention to buy the host country's products.

In addition to behavioral outcomes being mediated by attitude toward a host country (country image), up close, personal experiences in host countries offer new information about the country and create new ways of thinking and/or perception changes [44]. Bellany and Weinberg [46] argued that personal interactions can change stereotypes regarding other countries, which facilitates more authentic and honest communication with people from different nations. This sense of authenticity and honesty leads to greater acceptance of host country cultures and values. Authentic insights and direct experience of host country values and cultures also make students consider social or foreign policy issues from different perspectives. Mediated by positive attitudes toward host countries, their views can become flexible, less nationalistic, and even supportive of the host country's policy positions. In this regard, it has been shown that how exchange programs contribute to policy goals and related outcomes is not always guaranteed to be positive [13]. Although positive experiences tend to be associated with support for the host country's policy, negative personal experiences in a host country contribute to unfavorable images of it [10,52]. However, not many studies have investigated the influence of international education experiences on a nation's policy goals. The next hypothesis is a direct response to Scott-Smith's [13] call for an empirical study in this line of inquiry. It predicted the influence of attitude toward the host country on policy support. More substantial support for foreign policy in favor of the host country is to be expected when an individual has a more positive attitude toward it.

Hypothesis 3. Attitude toward the host country is positively associated with their support for the host country's foreign policy.

The comprehensive research model of this study is presented in Figure 1. 


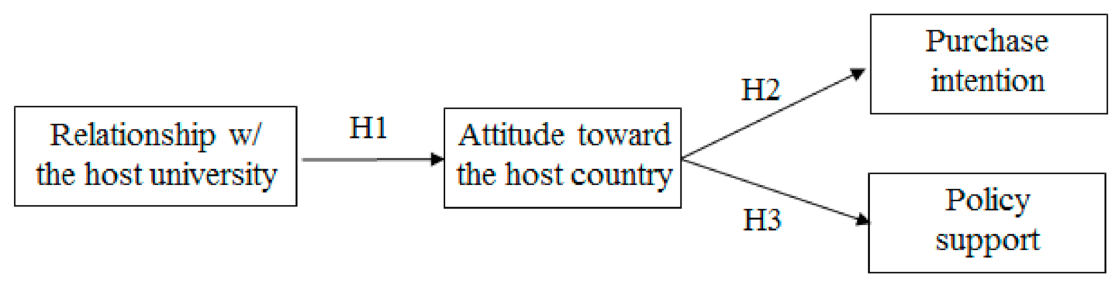

Figure 1. The proposed research model.

\section{Materials and Method}

\subsection{Survey Procedure}

This study examined Chinese students studying at South Korean universities. A survey was conducted online in November 2017, targeting Chinese respondents with experience studying in South Korean universities. A convenience sampling method was applied by posting recruiting flyers on several online bulletin boards, including university-based Chinese student associations and online communities. In particular, the researchers posted the flyers on the Chinese students' communities in WeChat and QQ, 2 of the most popular multimedia platforms in China (with the penetration rate of $70 \%$ to $85 \%$ [53]), to reach a large group of current and former Chinese students with educational experience in South Korea.

Responding to the recruiting flyers, a total of 240 respondents voluntarily participated in the online survey. On its first page, they were asked to read a consent form regarding ethical research principles, such as the study's purpose and length, confidentiality, and the voluntary nature of participation. It also identified the principal investigators and research institutions. Only those who read and agreed to the principles could begin the main questionnaire. The survey questionnaire was provided in Chinese to minimize foreign language-related errors. In addition to items measuring research variables (e.g., relationship with the university, attitude toward South Korea, purchase intention, policy support), the questionnaire asked for sociodemographic variables, such as age and gender, and key information regarding students' stays in South Korea including the length of stay, current academic status $(1=$ currently enrolled, $2=$ finished/graduated), residential status ( $1=$ staying in South Korea, 2 = staying in China), type of academic program ( $1=$ language program, $2=$ degree program $)$, and an overall evaluation of education quality.

\subsection{Measurements}

University-student relationship was measured using 15 items, which were adapted from Jo et al. [27] and Hon and Grunig [24]. The items measured the 4 dimensions of organization-public relationship, including control mutuality ( 4 items), trust ( 4 items), commitment ( 4 items), and satisfaction (3 items). Participants rated responses on a 5-point scale from 1 (not at all) to 5 (very much). A factor analysis found 1 underlying factor among the 15 items (eigenvalue $=8.205$; factor loading $=0.62 \sim 0.84$ ), accounting for $54.7 \%$ of the total variance, and thus, the average of 15 items was calculated for the relationship variable (Cronbach's $\alpha=0.939$ ).

Attitude toward the host country was measured using 4 items, modified from previous studies $[54,55]$ to fit the context of this study. The 4 items were measured on a 1 (not at all) to 5 (very much) scale $(\alpha=0.964)$. The level of purchase intention was measured by asking respondents about their willingness to buy products from the host country. Adopting Yang et al. [4], the study originally measured purchase intention using 3 statements on a 5-point scale, but one of them was excluded because it significantly weakened the internal consistency. Thus, 2 items were averaged for further analysis $(\alpha=0.816)$.

The extent to which respondents supported the host country's foreign policy (i.e., policy support) was measured by asking them about the South Korean government's decision to deploy the THAAD (Terminal High Altitude Area Defense) system in the southern part of the Korean Peninsula, which 
the Chinese government strongly opposed because it viewed the THAAD X-band radar system as a threat to Chinese national security. Both the Chinese leaders and citizens expressed resentment and concern about the deployment decision. Including 2 items adapted from Oh, Cheon, and Kim [56], 4 statements were used on a 5 -point scale ( $1=$ not at all, $5=$ very much) to measure respondents' level of policy support, represented by their understanding of, and agreement with, the Korean government's decision $(\alpha=0.934)$.

A total of 3 control variables were additionally included in the model. The respondents' current residency was measured whether they were staying in South Korea or in China at the point of data collection. In addition, perceived quality of lectures and facilities were measured respectively on a 5 -point scale from 1 (not at all) to 5 (very much). Measurement items are provided in Table 1.

Table 1. Measurement items.

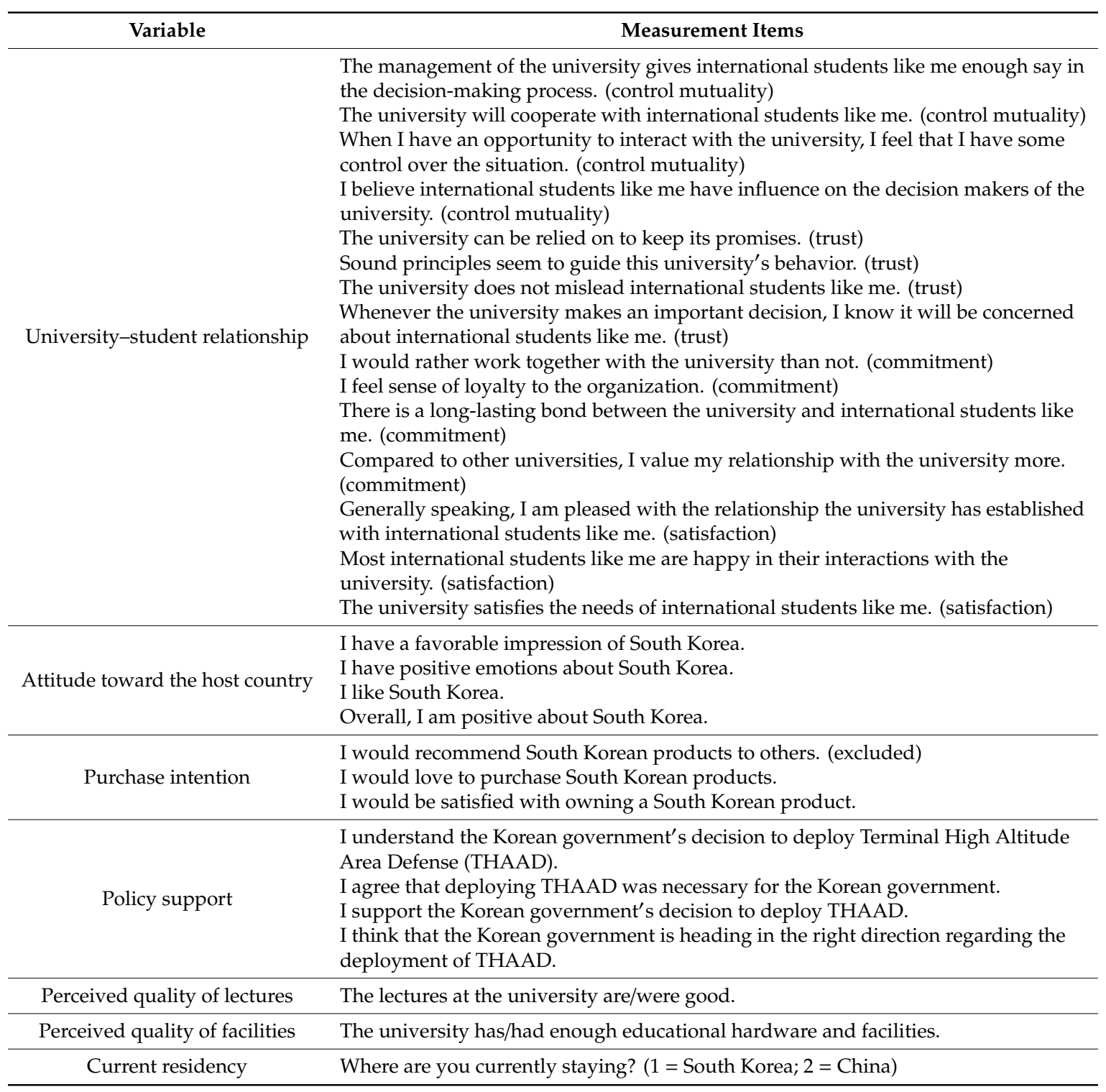

\section{Results}

\subsection{Descriptive Statistics}

Among the 240 collected responses, 5 were excluded because of significant missing values or effortless responses. Female respondents $(n=140,59.6 \%)$ outnumbered their male counterparts $(n=95$, 
$40.4 \%$ ), and the ages of respondents ranged between 20 and 31, with an average of $25.93(S D=2.559)$. About half reported that they had finished/graduated $(n=114,48.5 \%)$ and the other participants indicated that they were currently enrolled in a university program $(n=121,51.5 \%)$. Most respondents either had participated or were participating in degree programs $(n=189,80.4 \%)$ rather than language programs $(n=46,19.6 \%)$. In total, two-thirds of respondents were currently staying in South Korea ( $n=157,66.8 \%)$, and one-third had returned to China $(n=78,33.2 \%)$. Regarding length of stay in South Korea, 38.3\% of respondents reported less than 1 year $(n=90), 11.5 \%$ reported 1 to 2 years $(n=27), 37 \%$ reported 2 to 5 years $(n=87)$, and $13.2 \%$ reported over 5 years $(n=31)$. For the key variables, the mean score was the highest for the intention to buy South Korean products $(M=3.660$, $\mathrm{SD}=0.762)$, followed by attitude toward South Korea $(\mathrm{M}=3.523, \mathrm{SD}=0.844)$ and relationship with the host university $(M=3.355, S D=0.601)$. The mean for policy support was relatively low $(M=1.873$, $\mathrm{SD}=0.747$ ), which was far below the mid-point on the 5-point scale, with a maximum of 3.25.

\subsection{Hypothesis Testing}

To test the proposed hypotheses, path analysis was performed using the AMOS program. Path analysis is a regression-based statistical technique that examines the dependencies of a set of variables in a model simultaneously. The linkages among relationship with the university, attitude toward South Korea, and purchase intention and policy support were tested while controlling for the respondents' current residency and perceived quality of lectures and facilities. The influences of other individual properties (e.g., gender, age, length of stay in South Korea, enrolled vs. graduated) were not considered in the final path model because they showed no significant influence.

Overall, the path model showed a satisfactory level of goodness-of-fit, meaning the proposed path model fit the collected data well (see Figure 2). To evaluate model fitness, multiple indices were examined, including Chi-square statistics, goodness-of-fit index (GFI), adjusted goodness-of-fit index (AGFI), normed fit index (NFI), comparative fit index (CFI), the root-mean-square error of approximation (RMSEA), and standardized root mean square residual (SRMR). The proposed model showed satisfactory model fitness in terms of Chi-square statistics $\left(\chi^{2}{ }_{(3)}=0.978, p=0.807\right)$, which is the most conservative criterion to evaluate the goodness of fit. The model is assessed to be satisfactory when the $p$-value is greater than 0.05 , meaning no significant discrepancy between the proposed model and the data. Other indicators also met the recommended criteria [57-59]: GFI $=0.999(\geq 0.95)$; AGFI $=0.989(\geq 0.90) ; \mathrm{NFI}=0.997(\geq 0.95) ; \mathrm{CFI}=1.000(\geq 0.95) ; \mathrm{RMSEA}<0.001(<0.06) ; \mathrm{SRMR}=0.006$ $(<0.08)$.

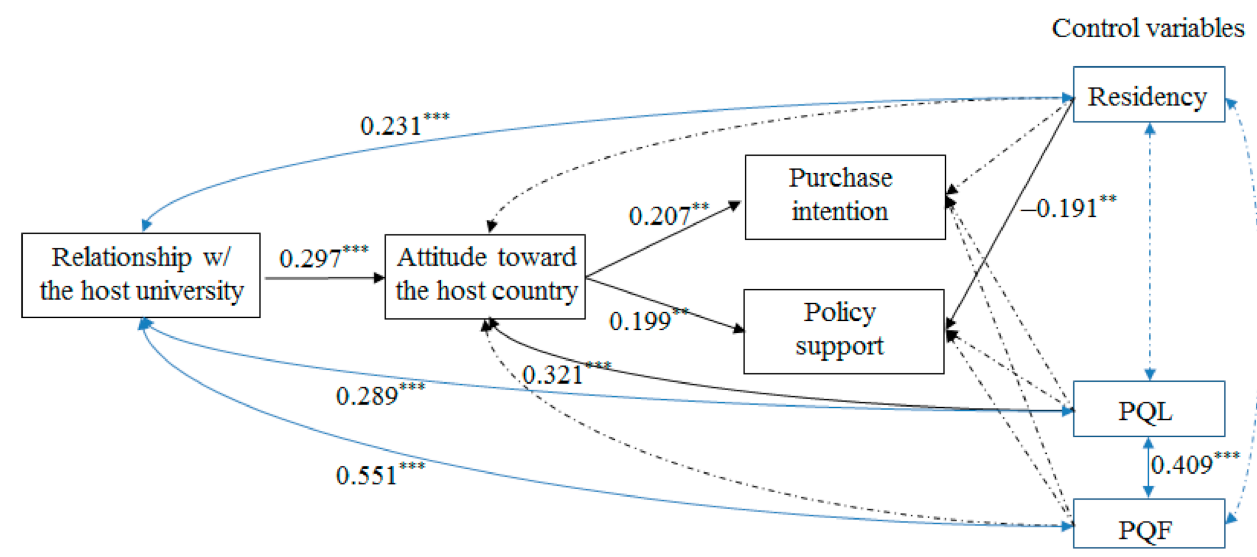

Figure 2. Path model results. ${ }^{* * *} p<0.001,{ }^{* *} p<0.01 ; \mathrm{PQL}=$ perceived quality of lectures; $\mathrm{PQF}=$ perceived quality of facilities. The solid lines represent significant path coefficients between variables, indicated by the standardized regression coefficients ( $($ ). Dashed lines represent nonsignificant relationships between variables. A single-headed arrow shows a causal relationship, and a double-headed arrow shows the covariances between the two variables. 
The first hypothesis predicted a positive association between university-student relationship and attitudes toward the host country. As hypothesized, the analysis revealed that perceived relationship with host university had a strong positive influence on attitude toward South Korea $(B=0.297, p<0.001$; $\mathrm{B}=0.417, \mathrm{SE}=0.092$ ). These results indicated that the university-student relationship is a significant predictor of attitude toward the host country.

The path between attitude toward host country and purchase intention was also significant, confirming H2 ( $B=0.207, p<01 ; \mathrm{B}=0.187, \mathrm{SE}=0.068$ ). Respondents with more positive attitudes toward South Korea reported greater intentions to purchase South Korean products. There was also a significant relationship found between the attitude toward and policy support for the host country $(B=0.199, p<0.01 ; B=0.176, S E=0.067)$; the more positive attitude Chinese students had toward South Korea, the more supportive they were toward the South Korean decision on THAAD. Thus, H3 was supported.

Although not hypothesized, the analysis showed some influences of control variables as shown in Figure 2 and Table 2 . The attitude toward host country was significantly influenced by perceived quality of lectures $(B=0.321, p<0.001 ; B=0.369, \mathrm{SE}=0.067)$, and the impact of perceived quality of facilities was also meaningful at a statistically marginal level $(B=0.128, p=0.057 ; \mathrm{B}=0.236, \mathrm{SE}=0.066)$. In addition, a positive relationship between current residency status and policy support was found. In particular, compared to those staying in South Korea, respondents who had returned to China tended to be less supportive of South Korea's THAAD policy $(B=-0.191, p<0.01 ; \mathrm{B}=-0.302$, $\mathrm{SE}=0.102)$.

Table 2. Path estimates in the path model.

\begin{tabular}{|c|c|c|c|c|c|c|c|}
\hline & & & ß & B & S.E. & C.R. & $p$ \\
\hline \multicolumn{8}{|c|}{ Hypothesized paths } \\
\hline Attitude & $\leftarrow$ & Relationship & 0.297 & 0.417 & 0.092 & 4.514 & $<0.001$ \\
\hline Purchase intention & $\leftarrow$ & Attitude & 0.207 & 0.187 & 0.068 & 2.741 & 0.006 \\
\hline Policy support & $\leftarrow$ & Attitude & 0.199 & 0.176 & 0.067 & 2.635 & 0.008 \\
\hline \multicolumn{8}{|c|}{ Controlled paths } \\
\hline Attitude & $\leftarrow$ & Residency & 0.061 & 0.110 & 0.098 & 1.115 & 0.265 \\
\hline Attitude & $\leftarrow$ & PQL & 0.321 & 0.369 & 0.067 & 5.541 & $<0.001$ \\
\hline Attitude & $\leftarrow$ & PQF & 0.128 & 0.126 & 0.066 & 1.905 & 0.057 \\
\hline Purchase intention & $\leftarrow$ & Residency & 0.061 & 0.099 & 0.104 & 0.953 & 0.340 \\
\hline Policy support & $\leftarrow$ & Residency & -0.191 & -0.302 & 0.102 & -2.968 & 0.003 \\
\hline Purchase intention & $\leftarrow$ & PQL & -0.102 & -0.106 & 0.077 & -1.379 & 0.168 \\
\hline Policy support & $\leftarrow$ & PQL & -0.136 & -0.139 & 0.076 & -1.837 & 0.066 \\
\hline Purchase intention & $\leftarrow$ & PQF & 0.117 & 0.104 & 0.064 & 1.616 & 0.106 \\
\hline Policy support & $\leftarrow$ & PQF & -0.075 & -0.065 & 0.063 & -1.034 & 0.301 \\
\hline \multicolumn{8}{|c|}{ Covariances } \\
\hline Relationship & $\leftrightarrow$ & Residency & 0.231 & 0.065 & 0.019 & 3.440 & $<0.001$ \\
\hline Relationship & $\leftrightarrow$ & PQL & 0.289 & 0.127 & 0.030 & 4.243 & $<0.001$ \\
\hline Residency & $\leftrightarrow$ & PQL & 0.089 & 0.031 & 0.023 & 1.362 & 0.173 \\
\hline PQL & $\leftrightarrow$ & PQF & 0.409 & 0.257 & 0.044 & 5.785 & $<0.001$ \\
\hline Relationship & $\leftrightarrow$ & PQF & 0.551 & 0.284 & 0.038 & 7.384 & $<0.001$ \\
\hline Residency & $\leftrightarrow$ & PQF & -0.008 & 0.003 & 0.026 & -0.115 & 0.908 \\
\hline
\end{tabular}

Note. $\mathrm{PQL}=$ perceived quality of lectures; PQF = perceived quality of facilities; A single-headed arrow shows a causal relationship, and a double-headed arrow shows the covariances between the two variables.

\section{Discussion}

This study examined the influence of international education experience (represented by the university-student relationship) on country-related outcomes, including attitude toward the host country, purchase intention, and policy support. The proposed model was tested with a survey dataset of Chinese students who had or who were currently studying at university in South Korea. The analysis found that university-student relationships perceived by Chinese students were significantly related to their attitudes toward South Korea, which consequently influenced their willingness to buy Korean products and to support the Korean government's foreign policy. These results support the contention 
that personal experience with another country is an important means of building individuals' images of and subsequent support toward that country (i.e., policy support and willingness to visit).

This study provides theoretical and practical contributions in several ways. Examining the general supposition that the international education benefits host countries, this study extended the OPR framework to the international education experience and subsequent country-related outcomes. The results imply that an international student's perception of his/her relationship with a host university is a meaningful indicator of his/her international education experience. The OPR concept and measures take the multifaceted meaning of international education experience into consideration, and this study demonstrated its potential as a useful tool.

This study also provides evidence consistent with the previous studies $[8,11,60]$ of new perspectives in public diplomacy, including nonstate actors' roles (e.g., universities) in public diplomacy. Chinese students' perceptions of their relationships (based on control mutuality, trust, commitment, and satisfaction) with the Korean universities they attended are related to their attitudes toward South Korea, their intentions to purchase Korean products, and their opinions regarding Korean foreign policy. As Tuch [40] and Sharp [41] have explained, public diplomacy is a way for the foreign public to understand a host country's ideas, values, culture, interests, and policies. The findings of this study show evidence of this influence.

In the eyes of Chinese students, Korean universities represent two identities-university and country. Given the significant influence of the perceived relationship on attitude toward the host country, it is important to notice that the positive relationship-attitude linkage can move in both directions. In other words, while a positive OPR leads to a positive attitude toward the host country, a negative OPR also leads to a negative attitude toward the host country. Therefore, universities should genuinely endeavor to build and maintain positive relationships with international students because failed relationships extend beyond universities into their evaluations of host countries.

This study also found an association between a positive attitude toward the host country built on positive OPR and individuals' willingness to buy the host country's products. This finding corresponds to a longstanding belief that a positive national image affects foreign consumers' product evaluations and purchase-related decisions and behaviors. This study confirmed the two-step OPR-attitude-behavioral intention path model consistently with the previous studies [47,49-51].

Moreover, the empirical data in this study showed that a positive attitude toward the host country, developed based on a favorable relationship with host universities, led to policy support in favor of the host country. However, in interpreting the results, the relationships among international education, country image, and policy support should not be overstated because of many confounding factors such as individual and contextual variables, as Lima [43] pointed out. Particularly, foreign policy often involves keen national interests, gains and losses, and uncompromising conflicts between and among the nations. In fact, the THAAD issue, which was used to measure foreign policy support in this study, is a very sensitive national security issue between South Korea and China, concerning the deployment of a U.S. missile system on South Korean soil. Nevertheless, it is meaningful that this study found a significant attitude-policy support linkage. However, it should be noted that the mean score of Chinese support for the South Korean policy on the THADD issue was very low $(\mathrm{M}=1.87$, maximum $=3.25$ out of 5-point scale) and highly skewed to the negative opinion. It only moved between the negative and the neutral. It makes sense that having a positive opinion about another country's foreign policy is hard especially when it conflicts with the interests of one's home country. It seems that living and studying in South Korea could have made Chinese students feel more sympathetic or at least hold more objective views regarding South Korea and South Korean foreign policy.

Finally, in regard to the influence of control variables, it is intuitive that perceived quality of lectures and facilities was associated with attitude toward the host country because the most important goal of international education is to provide satisfactory education service to students. In addition, the respondents' current residency status (currently in South Korea vs. back in China) exerted a strong influence on their levels of policy support as much as their attitudes toward South Korea did. 
Respondents who had returned to China reported lower levels of support for South Korea's THAAD policy than those currently living in South Korea. One reason for this is likely the different media environments between China and South Korea. Stationing the U.S. missile system with high power radar in South Korea sparked Chinese security concerns about the U.S. surveillance and South Korea-US alliance supported this system in place to counter North Korea's threat in the region. The news media in China and South Korea covered this thorny issue extensively during the time that this study was being conducted. Consequently, respondents living in China were more exposed to Chinese media coverage, which reflected the perspective of the Chinese government. In contrast, respondents living in South Korea were likely more exposed to South Korean media coverage, which reflected the South Korean perspective. The influence of media consumption on public perception of foreign policy thus calls for further investigation in future studies.

The key findings of this study highlight the importance of international education as a public diplomacy domain. The linkage of international students-university relationship (OPR), attitude toward host country, and policy support (neutralizing negative opinion in this study) deserves more attention for conceptual development in public diplomacy as well as international education scholarship. This study confirms that South Korean universities are effective soft power resources to affect Chinese students. As Yun and Vibber [42] stated, "the presence of foreign students is just the start of a dynamic long second-round sociological process for recalibrating real soft power" (p. 77).

From the public diplomacy perspective, universities are not part of any purposive government-run public diplomacy programs but independent nonstate public diplomacy actors. Given that many scholars have emphasized the role of nonstate actors, such as higher education institutions, in contemporary public diplomacy $[8,11,60]$, the findings of this study highlight the importance of university-hosted international education programs and direct relationships with international students. While government-driven public diplomacy activities are often perceived as propaganda, everyday experiences with universities involve more two-way interactions that contribute to relationship building. Thus, it is imperative that universities and their constituents recognize their roles as nonstate public diplomacy actors representing their countries and that governments support their universities.

In spite of the many implications this study offers, it has several limitations and the results should be interpreted with caution. During the data collection period, the Chinese government and Chinese leaders declared a boycott of Korean products and tours to South Korea because of the Korean government's deployment of THAAD. Presumably, this development influenced respondents' reported purchase intentions. In fact, respondent intention to recommend Korean products, which was removed from the analysis, was not significantly associated with other measures of the same variable, decreasing the overall reliability of the measures. This implies that individuals hesitated to express support for Korean products in public because of the negative opinion climate toward South Korea. Indeed, respondents likely reported lower purchase intentions during the data collection period than they would have under normal circumstances. Additionally, these circumstances may have suppressed the impact of university-student relationships on other country-related outcomes. Presumably, the association between the university-student relationship and attitude toward South Korea would be greater in a more peaceful political situation.

Another limitation of this study was embedded in its sample. The study recruited both current and former Chinese students from multiple Korean universities because previous studies identified sampling students from a single university as a limitation (e.g., $[25,27,28,30])$. However, because a proper sample frame of Chinese students was not accessible due to national privacy laws and subordinate university policies, we relied on online data collection mainly through WeChat and QQ. Although these channels are known as the most popular Chinese social media sites [53], relying on a convenience sampling method does not guarantee representativeness and requires cautious interpretation of the results.

This study adopted a single issue (THAAD) to measure foreign policy support. However, the complex nature of foreign policy requires future studies to examine if the current findings are consistent 
across diverse foreign policies in different cultures. In addition, as Lima [43] cautioned, many other factors can affect the relationships between international education, country image, and policy support. For example, individual differences (e.g., language skills, perceived cultural familiarity) may have potential effects on the perception of the host university and/or host country, but they were not considered in this study. Thus, our results should be interpreted according to these considerations. Based on their geographical proximity and similar cultural background (e.g., Eastern culture, Confucian orientation), South Korea and China have a long history together. Their interactions have become more active in the past few years, particularly in educational exchange, product trade, and tourism. This may have created a unique study context. It is expected that future studies will be conducted in different settings (e.g., investigating the experiences of Chinese students in a Western country, such as the U.K. or the U.S., or those of American or European students in South Korea) to determine whether or not the current findings are consistent across contexts.

\section{Conclusions}

Based on a survey of Chinese students in South Korean universities, this study showed the potency of educational experience in a foreign country in producing diverse outcomes related to the country, including attitude toward it, purchase intentions, and support for its policy. We introduced the OPR concept as a comprehensive indicator of an international student's experience with the host university. We also presented the role of higher education institutions as important nonstate actors in public diplomacy. This study's key contribution is its expansion of the scope of research on international education outcomes by its proposal of an integrated model incorporating a public relations framework (i.e., OPR) and a country-level perspective (i.e., public diplomacy).

In a highly globalized education system, internationalization is a prerequisite for the sustainable development of higher education institutions; recruiting qualified international students and maintaining a good relationship with them are necessary [61]. This approach directly corresponds to the attributes of diversity and inclusion, focusing on international and intercultural interactions and interdependence, which are addressed in the Sustainable Development Goals (SDGs) of higher education programs [18]. We believe that this study provides educational institutions with a useful guideline for building and maintaining mutually beneficial relationships with international students. It is also worth noting that, from these institutional efforts, host countries can realize benefits such as more positive attitudes toward the country, greater intention to buy its products, and stronger support for its foreign policy. These affirmative outcomes on the country-level are pertinent to the internationalization of educational institutions as part of public diplomacy activities.

Author Contributions: Conceptualization, H.H., S.L., and Q.T.; data curation, H.H. and Q.T.; formal analysis, H.H., S.L., and Q.T.; investigation, H.H., S.L., and Q.T.; methodology, H.H. and Q.T.; project administration, H.H. and Q.T.; visualization, H.H. and S.L.; writing-original draft, H.H., S.L., and Q.T.; writing-review and editing, H.H. and S.L. All authors have read and agreed to the published version of the manuscript.

Funding: This research received no external funding.

Conflicts of Interest: We found no potential conflicts of interest.

\section{References}

1. UNESCO. International Student Mobility in Tertiary Education. Available online: http://data.uis.unesco.org (accessed on 13 August 2019).

2. Statistics Korea. Korean Social Trend 2017. Available online: http://sri.kostat.go.kr (accessed on 26 March 2019).

3. Lee, S.; Toth, E.L.; Shin, H. Cognitive categorization and routes of national reputation formation: US opinion leaders' views on South Korea. Place Brand. Public Dipl. 2008, 4, 272-286. [CrossRef]

4. Yang, S.-U.; Shin, H.; Lee, J.-H.; Wrigley, B. Country Reputation in Multidimensions: Predictors, Effects, and Communication Channels. J. Public Relat. Res. 2008, 20, 421-440. [CrossRef] 
5. Paige, R.M.; Fry, G.W.; Stallman, E.M.; Josić, J.; Jon, J. Study abroad for global engagement: The long-term impact of mobility experiences. Intercult. Educ. 2009, 20, S29-S44. [CrossRef]

6. Sindt, P. Internationalization and Higher Education: Understanding the Impact of Short-Term Study Abroad. Ph.D. Thesis, Arizona State University, Tempe, AZ, USA, 2007.

7. Westerheijden, D. Internationalisation and Its Quality Assurance: Modern European Platform Higher Education Modernisation; European Center for Strategic Management of Universities: Brussels, Belgium, 2010.

8. Cull, N.J. Public Diplomacy: The Lessons from the Past; Figueroa Press: Los Angeles, CA, USA, 2009.

9. Gilboa, E. Searching for a Theory of Public Diplomacy. Ann. Am. Acad. Polit. Soc. Sci. 2008, 616, 55-77. [CrossRef]

10. Han, D.; Chen, D.; Fang, C. Images of the United States: Explaining the Attitudes of Chinese Scholars and Students in the United States. Chin. J. Int. Polit. 2013, 6, 183-207. [CrossRef]

11. Melissen, J. The New Public Diplomacy: Soft Power in International Relations; Palgrave: New York, NY, USA, 2005.

12. Snow, N. International Exchanges and the U.S. Image. Ann. Am. Acad. Polit. Soc. Sci. 2008, 616, 198-222. [CrossRef]

13. Scott-Smith, G. Mapping the Undefinable: Some Thoughts on the Relevance of Exchange Programs within International Relations Theory. Ann. Am. Acad. Polit. Soc. Sci. 2008, 616, 173-195. [CrossRef]

14. Ahmad, S. Internationalization of higher education: A tool for sustainable development. OIDA Int. J. Sustain. Dev. 2012, 4, 79-90.

15. Clerk, S.; Stephenson, G.K. Is higher education internationalisation sustainable? University World News, 13 July 2019. Available online: https://www.universityworldnews.com/post.php?story=20190708113340830 (accessed on 16 November 2020).

16. Ilieva, R.; Beck, K.; Waterstone, B. Towards sustainable internationalisation of higher education. High. Educ. 2014, 68, 875-889. [CrossRef]

17. Jones, E.; De Wit, H. Globalized internationalization: Implications for policy and practice. Available online: https://www.academia.edu/6528914/Globalized_Internationalization_Implications_for_Policy_and_ Practice (accessed on 16 November 2020).

18. Kioupi, V.; Voulvoulis, N. Sustainable Development Goals (SDGs): Assessing the Contribution of Higher Education Programmes. Sustainability 2020, 12, 6701. [CrossRef]

19. Wilson, L. The Internationalisation of Higher Education and Research: European Policies and Institutional Strategies. In Possible Futures: The Next 25 Years of the Internationalization of Higher Education; De Wit, H., Hunter, F., Johnson, L., Van Liempd, H.-G., Eds.; European Association for International Education: Amsterdam, The Netherlands, 2013; pp. 28-33.

20. Bruning, S.D. Examining the role that personal, professional, and community relationships play in respondent relationship recognition and intended behavior. Commun. Q. 2000, 48, 437-448. [CrossRef]

21. Bruning, S.D. Relationship building as a retention strategy: Linking relationship attitudes and satisfaction evaluations to behavioral outcomes. Public Relat. Rev. 2002, 28, 39-48. [CrossRef]

22. Bruning, S.D.; Ledingham, J.A. Relationships between organizations and publics: Development of a multi-dimensional organization-public relationship scale. Public Relat. Rev. 1999, 25, 157-170. [CrossRef]

23. Bruning, S.D.; Ledingham, J.A. Perceptions of relationships and evaluations of satisfaction: An exploration of interaction. Public Relat. Rev. 2000, 26, 85-95. [CrossRef]

24. Hon, L.C.; Grunig, J.E. Guidelines for Measuring Relationships in Public Relations; Institute for Public Relations: Gainesville, FL, USA, 1999; Available online: www.instituteforpr.org (accessed on 26 March 2019).

25. Hon, L.; Brunner, B. Measuring public relationships among students and administrators at the University of Florida. J. Commun. Manag. 2002, 6, 227-238. [CrossRef]

26. Huang, Y.-H. OPRA: A Cross-Cultural, Multiple-Item Scale for Measuring Organization-Public Relationships. J. Public Relat. Res. 2001, 13, 61-90. [CrossRef]

27. Jo, S.; Hon, L.C.; Brunner, B.R. Organisation-public relationships: Measurement validation in a university setting. J. Commun. Manag. 2005, 9, 14-27. [CrossRef]

28. Ki, E.-J.; Hon, L.C. Testing the linkages among the organization-public relationship and attitude and behavioral intentions. J. Public Relat. Res. 2007, 19, 1-23.

29. Huang, Y. Public Relations Strategies and Organization-Public Relationships. In Proceedings of the Annual Conference of the Association for Education in Journalism and Mass Communication, Baltimore, MD, USA, 5-8 August 1998. 
30. Sung, M.; Yang, S.-U. Student-university relationships and reputation: A study of the links between key factors fostering students' supportive behavioral intentions towards their university. High. Educ. 2008, 57, 787-811. [CrossRef]

31. Yang, S.-U.; Alessandri, S.W.; Kinsey, D.F. An Integrative Analysis of Reputation and Relational Quality: A Study of University-Student Relationships. J. Mark. High Educ. 2008, 18, 145-170. [CrossRef]

32. Mohammed, R. Organization-public Relationships Practices in University Setting. Procedia Soc. Behav. Sci. 2014, 155, 484-489. [CrossRef]

33. Beaudoin, C.E. The independent and interactive antecedents of international knowledge. Int. Commun. Gaz. 2004, 66, 459-473. [CrossRef]

34. Kunczik, M. Images of Nations and International Public Relations; Lawrence Erlbaum: Mahwah, NJ, USA, 1997.

35. Nisbet, E.C.; Nisbet, M.C.; Scheufele, D.A.; Shanahan, J.E. Public Diplomacy, Television News, and Muslim Opinion. Harv. Int. J. Press. 2004, 9, 11-37. [CrossRef]

36. Byrne, C.; Hall, R. Realising Australia's international education as public diplomacy. Aust. J. Int. Aff. 2013, 67, 419-438. [CrossRef]

37. Kim, J. Public relations and public diplomacy in cultural and educational exchange programs: A coorientational approach to the Humphrey Program. Public Relat. Rev. 2016, 42, 135-145. [CrossRef]

38. Eastwood, B.M. A Note on the New Face of Citizen Diplomacy: Education City and American Universities in the Middle East. Am. Foreign Policy Interests 2007, 29, 443-449. [CrossRef]

39. Gilboa, E. Media diplomacy: Conceptual divergence and applications. Int. J. Press Polit. 1998, 3, 56-75. [CrossRef]

40. Tuch, H. Communicating with the World: US Public Diplomacy Overseas; St. Martin Press: New York, NY, USA, 1990.

41. Sharp, P. Revolutionary States, Outlaw Regimes and the Techniques of Public Diplomacy. In The New Public Diplomacy: Soft Power in International Relations; Melissen, J., Ed.; Palgrave: New York, NY, USA, 2005; pp. 106-123.

42. Fitzpatrick, K.R. Privatized Public Diplomacy. In Toward to a New Public Diplomacy; Seib, P., Ed.; Palgrave: New York, NY, USA, 2009; pp. 155-172.

43. De Lima, A.F. The role of international educational exchanges in public diplomacy. Place Brand. Public Dipl. 2007, 3, 234-251. [CrossRef]

44. Kelman, H.C. Changing Attitudes Through International Activities. J. Soc. Issues 1962, 18, 68-87. [CrossRef]

45. Hayden, C. Applied Public Diplomacy: A Marketing Communications Exchange Program in Saudi Arabia. Am. Behav. Sci. 2009, 53, 533-548. [CrossRef]

46. Bellany, C.; Weinberg, A. Educational and cultural exchanges to restore America's image. Wash. Q. 2008, 31, 55-68. [CrossRef]

47. Kotler, P.; Gertner, D. Country as brand, product, and beyond: A place marketing and brand management perspective. J. Brand Manag. 2002, 9, 249-261. [CrossRef]

48. Lee, S.; Rodriguez, L.; Sar, S. The influence of logo design on country image and willingness to visit: A study of country logos for tourism. Public Relat. Rev. 2012, 38, 584-591. [CrossRef]

49. Papadopoulos, N.; Heslop, L. Country equity and country branding: Problems and prospects. J. Brand Manag. 2002, 9, 294-314. [CrossRef]

50. Jaffe, E.D.; Nebenzahl, I.D. National Image and Competitive Advantage: The Theory and Practice of Country-of-Origin Effect; Copenhagen Business School Press: Copenhagen, Denmark, 2001.

51. Anholt, S. Competitive Identity: The New Brand Management for Nations, Cities, and Regions; Palgrave McMillan: New York, NY, USA, 2003.

52. Yun, S.-H.; Vibber, K. The Strategic Values and Communicative Actions of Chinese Students for Sociological Korean Public Diplomacy. Int. J. Strat. Commun. 2012, 6, 77-92. [CrossRef]

53. Dragon Social. 10 Most Popular Social Media Sites in China. Available online: https://www.dragonsocial. net/blog/social-media-in-china/ (accessed on 13 August 2019).

54. Jun, J.W.; Choi, C.W. Effects of country of origin and country brand attitude on nonprescription drugs. J. Target. Meas. Anal. Mark. 2007, 15, 234-243. [CrossRef]

55. Oh, M.-Y.; Park, J.; Jang, J. A study on factors of affecting country image. Korean J. Advert. 2003, 14, $149-177$.

56. Oh, K.S.; Cheon, M.J.; Kim, H.K. Analyzing the Effects of Policy PR on the Policy Support, Government Trust. J. Korea Contents Assoc. 2013, 13, 190-202. [CrossRef] 
57. Hu, L.-T.; Bentler, P.M. Cutoff criteria for fit indexes in covariance structure analysis: Conventional criteria versus new alternatives. Struct. Equ. Model. A Multidiscip. J. 1999, 6, 1-55. [CrossRef]

58. Iacobucci, D. Structural equations modeling: Fit Indices, sample size, and advanced topics. J. Consum. Psychol. 2010, 20, 90-98. [CrossRef]

59. Kline, R.B. Principles and Practice of Structural Equation Modeling; Guilford Press: New York, NY, USA, 2005.

60. Ross, C. Pillars of public diplomacy. Harv. Int. Rev. 2003, 25, 22-27.

61. Khorsandi, T.A. A Critical Policy Analysis of Internationalization in Postsecondary Education: An Ontario Case Study; Western University: London, ON, Canada, 2014.

Publisher's Note: MDPI stays neutral with regard to jurisdictional claims in published maps and institutional affiliations.

(C) 2020 by the authors. Licensee MDPI, Basel, Switzerland. This article is an open access article distributed under the terms and conditions of the Creative Commons Attribution (CC BY) license (http://creativecommons.org/licenses/by/4.0/). 